\title{
5q35 microduplication syndrome
}

INSERM

\section{Source}

INSERM. (1999). Orphanet: an online rare disease and orphan drug data base. 5 q35

microduplication syndrome. ORPHA:228415

The newly described $5 q 35$ microduplication syndrome is associated with microcephaly, short stature, developmental delay and delayed bone maturation. 